Article

\title{
Instagram Influencers as Superwomen: Influencers' Lifestyle Presentations Observed Through Framing Analysis
}

\author{
Sarah Devos *, Steven Eggermont, and Laura Vandenbosch \\ School for Mass Communication Research, KU Leuven, Belgium \\ * Corresponding author (sarah.devos@kuleuven.be)
}

Submitted: 19 July 2021 | Accepted: 9 September 2021 | Published: 24 February 2022

\begin{abstract}
Female Instagram influencers presumably manipulate their online presentations to conform to the "superwoman ideal" (i.e., the idea that women have to excel in multiple roles). Knowledge of how they build such presentations is important to understand how young women's perception of the superwoman ideal might be affected by social media. As such, the current content analytical study ( $N=1,200$ posts, 60 influencers) examined how female health and beauty influencers present themselves in accordance with the superwoman ideal and whether such presentations vary by culture (i.e., the US, Belgium, and China). Inductive framing analysis revealed that they highlight their excellence in six roles, which focus on appearance, relationships, activities, achievements, wisdom, and expertise. Additional multilevel analyses suggested that besides beauty, it is most important to be perceived as an exciting and experienced individual. These roles are generalizable across cultures, implying that the superwoman ideal is presented identically worldwide.
\end{abstract}

\section{Keywords}

content analysis; framing analysis; Instagram influencers; superwoman ideal

Issue

This article is part of the issue "New Narratives for New Consumers: Influencers and the Millennial and Centennial Generations" edited by Luis M. Romero-Rodríguez (Rey Juan Carlos University), Santiago Tejedor (Autonomous University of Barcelona), and Inmaculada Berlanga (International University of La Rioja).

(C) 2022 by the author(s); licensee Cogitatio (Lisbon, Portugal). This article is licensed under a Creative Commons Attribution 4.0 International License (CC BY).

\section{Introduction}

The lifestyles of most top Instagram influencers appear perfect to their followers (Chae, 2018), yet we know little about how they build such lifestyles. Female influencers likely engage in framing practices to comply with the superwoman ideal, which refers to the-predominantly Western-societal idea that women should "have it all" (e.g., be beautiful, have a successful career; McRobbie, 2010). This knowledge is important because the superwoman ideal is partially responsible for the role overload (i.e., being overwhelmed by the total number of roles one has to fulfill) experienced by a significant portion of young women (De Lenne et al., 2018; Glynn et al., 2009).

Drawing upon the principles of framing theory (Entman, 1993), the current study (60 influencers, 1,200 posts) aims to shed light on female Instagram influencers' lifestyle presentations by examining how macro- (i.e., minimum 10,000 followers) and mega- (i.e., minimum 100,000; Oliveira et al., 2019) influencers strategically combine visual (i.e., picture/video) and textual information to present themselves as excellent in multiple roles. Furthermore, contextual elements, such as sexualization and the number of likes, might shape how the audience interprets the superwoman ideal and which roles to focus on. As such, this study explores the extent to which influencers show themselves in a sexualized manner across roles and whether differences between roles exist in the number of likes they receive. Given that influencers presumably frame their lifestyle according to their pre-existing cultural beliefs, they might highlight certain roles more than others, depending on the 
dominant values in their culture. Thus, we investigate female influencers from three distinctive cultures: US, Belgium, and China.

\subsection{Influencers as Superwomen: Beyond Beauty}

Instagram influencers have become famous through their Instagram profiles and position themselves as experts on one or several topics of interest (Khamis et al., 2017). The most popular topics are beauty, fashion, fitness, and food, which are predominantly approached by female influencers (Marwick, 2015). Influencers can be classified into four categories, depending on their number of followers: a) nano $(0-1,000)$, b) micro $(1,000-10,000), c)$ macro $(10,000-100,000)$, and d) mega (above 100,000; Oliveira et al., 2019).

Previous studies on female influencers have predominantly focused on their (sexualized) appearances, and the findings suggested that they edit their posts, wear revealing clothes, and take on sexualized poses (Hund, 2017). Popular female influencers are highly criticized for such presentations, as they might trigger their followers-especially young women - to behave in a similar manner (Pilgrim \& Bohnet-Joschko, 2019).

Although their appearances typically comply with the dominant norms of physical appearance, they do not solely focus on their beauty (Djafarova \& Trofimenko, 2019). Women in today's society are encouraged to "have it all," meaning that they should build a successful career while also having a flourishing social life, interesting hobbies, and a lovely family (McRobbie, 2010; Sumra \& Schillaci, 2015). The urge to concurrently excel in multiple life aspects, which is referred to as the superwoman ideal (McRobbie, 2010; Sumra \& Schillaci, 2015), stems from the gradual shift in role expectations women have experienced over the past years. Besides taking care of their household, they are now concerned with successfully performing in multiple roles (Sumra \& Schillaci, 2015). Although superwomen are expected to excel in multiple roles concurrently, some roles (e.g., successful career) might be more important to fulfill than others (e.g., practicing sports; Heather, 2008).

Research among followers of top female influencers has indicated that their lifestyle presentations comply with the superwoman ideal, yet systematic research on this subject is missing (Chae, 2018). How influencers build their lifestyle exactly and strategically focus on certain roles they fulfill can further be understood from the perspective of framing theory (Entman, 1993).

\subsection{Understanding Influencers' Lifestyle Presentations from the Perspective of Framing Theory}

Framing is defined as "selecting some aspects of a perceived reality and making them more salient" and refers to the manner in which the media present a topic (Entman, 1993, p. 52). Through carefully selecting and highlighting particular elements of a story, the media draw attention to them to influence individuals' perception of that story (Van Gorp, 2007). Hence, they provide a certain meaning to a message, also known as a frame, which guides how individuals process and interpret that message (Entman, 1993). Such frames generally emerge from a combination of visual and textual elements (Van Gorp, 2007).

Although framing theory is mostly used in political communication (Tewksbury \& Scheufele, 2009), content analyses on social media have suggested that this theory can also provide an explanatory framework for entertainment media. Fountaine (2017) examined how female politicians framed themselves on Twitter and recognized two clear frames: one focusing on status as a busy politician (i.e., busy local MP), and the other focusing on relations with voters (i.e., relational politician). The politicians used these frames in varying degrees across their presentations. Moreover, they were nonexclusive, meaning that elements of both frames were often recognized within the same tweet. Such research suggests that women emphasize multiple roles in their online presentations.

Female influencers' lifestyle presentations in relation to the superwoman ideal can also be understood from the perspective of framing theory. The superwoman ideal implies that they highlight various events (e.g., family gatherings and business trips) to emphasize that they are doing well in this role (Leban et al., 2020). Framing theory suggests that each element of the Instagram post (i.e., picture/video and caption) should focus on this highlighted role. Hence, by using framing practices to accentuate different roles in different posts, female influencers can present themselves as complying with the superwoman ideal (Leban et al., 2020).

As no study has yet investigated which roles influencers emphasize, this study first inductively explores the elements (i.e., picture/video and caption) of popular female influencers' profile posts to reveal the recurrent roles (RQ1a). Not all roles of the superwoman ideal are equally important (McRobbie, 2010); some of them (e.g., being smart) might also be less suitable to cover in an entertaining Instagram post (Schreurs \& Vandenbosch, 2021). As such, the current study also aims to deductively examine the extent to which each of the previously recognized roles occur (RQ1b). We thus assume that female influencers illustrate their compliance with the superwomen ideal by highlighting different roles across Instagram posts. However, the study on female politicians' framing on Twitter suggests that multiple roles can be promoted in a singular post (Fountaine, 2017). As such, the second research question explores the extent to which the recognized roles co-occur within posts (RQ2).

Moreover, some contextual elements may be so prominent that they deserve additional attention when studying the occurrence of female roles. Sexualization (i.e., to evaluate someone in terms of their physical appearance and sexiness; APA Task Force on the 
Sexualization of Girls, 2007) might be such an element. Instagram's visual nature suggests that sexual attractiveness is an essential aspect to focus on, regardless of the emphasized role (Hund, 2017). Compliance with the prevailing standards of beauty and sexiness becomes so important that it is frequently accentuated while focusing on specific appearance- and non-appearance-related roles. Additionally, consistent sexualization corresponds with the ubiquitous "beauty is good" stereotype, which describes beauty as an essential precondition to be successful in other roles (Northup \& Liebler, 2010). Even non-appearance-related roles are thus likely to be presented in a sexualized manner. By doing this, influencers can contribute to the idea that, overall, women have to be sexy and appealing (Pilgrim \& Bohnet-Joschko, 2019). As such, the third research question asks to what extent influencers present themselves in a sexualized manner across different roles (RQ3).

Next, the metric information (i.e., likes) accompanying posts is also relevant to be examined. Some roles presumably receive more likes than others, which allows followers to detect the most prestigious roles to fulfill. Prior research has shown that, for instance, family posts receive an abundance of likes (Park \& Lee, 2017), which suggests that having a lovely family is highly appreciated by the audience. Young women might attach greater importance to these roles than other less liked roles (Mascheroni et al., 2015). Hence, the fourth research question examines whether the number of likes varies across roles (RQ4).

The knowledge that follows from answering these research questions will help us to understand how young women's construction of the superwoman ideal can be affected by social media. Framing theory explains that individuals organize and interpret information using cognitive schemas, which are described as mental structures about a particular topic (Entman, 1993; Scheufele, 2004). Women presumably also possess schemas about the superwoman ideal, and influencers' presentations might activate and/or modify these schemas (Heather, 2008; Mensinger et al., 2007). As such, young women may perceive frequently highlighted roles as important to focus on and even add new roles to their schemas. Frequent activation (i.e., exposure) results in chronic accessibility, which implies that young women actively use these schemas to shape their own lifestyles (Scheufele, 2004).

Moreover, sexualized content and metric information (i.e., likes) might affect the construction of superwoman schemas. According to social cognitive theory, individuals are more likely to model reinforced behaviors (Bandura, 2001). Roles that receive more likes are thus presumably perceived as good and important to comply with. Additionally, sexualized content draws more attention than nonsexual content, which implies that roles depicted in a sexualized manner can be memorized better (Wirtz et al., 2018). However, sexualized content can also interfere with the highlighted role (e.g., nursing a baby in lingerie). Young women might perceive the influ- encer as less successful in that domain and neglect the emphasized role (Harrison \& Secarea, 2010).

\subsection{Superwoman Lifestyle: Different Interpretations Across the Globe?}

Generally, the meaning of a frame is rooted in a cultural context and thus based on pre-existing ideas (Van Gorp, 2007). Culture refers to the characteristics of a particular group of people sharing common values and ideas, which they use to provide meaning to messages and events (Gamson \& Modigliani, 1989; Van Gorp, 2007). Thus, how a message is framed depends on cultural beliefs, and slight differences in focus between cultures are likely to occur (Van Gorp, 2007).

The superwoman ideal has emerged from modern Western societal values and matches the idea of the "American dream," which denotes that anyone can become successful if they work hard enough (Glynn et al., 2009; Sumra \& Schillaci, 2015). Therefore, the superwoman concept tends to be rather individualistic, as it stresses women's own responsibility for success in multiple roles (Singelis et al., 1995). These roles are of varying importance, as young women in such cultures are typically encouraged to build a successful career before starting a family (Heather, 2008; McRobbie, 2010). However, Western cultures also differ from each other, as individualism can be divided into horizontal (i.e., equality) and vertical (i.e., inequality) variants (Singelis et al., 1995). West Europeans (e.g., Belgium) tend toward the horizontal axis as they value personal development and experiences over competition (Schwartz, 2014). For them, a superwoman is mainly occupied with self-development and exploration. North Americans (e.g., the US), on the other hand, tend toward the vertical axis as they encourage competition and progress (Schwartz, 2014).

However, globalization processes have ensured that this concept is also adopted by collectivistic cultures, such as China (Fang \& Walker, 2015). Especially due to the global nature of social media, the self-presentation styles of Western influencers can be easily adopted by non-Western influencers (Schroeder, 2016). Yet, their presentations might still reflect their cultural background, as they are assumed to prioritize different roles. As such cultures emphasize relationships and solidarity (Schwartz, 2014), their idea of a superwoman presumably focuses more on taking good care of the family.

Thus, we assume that different cultures define a superwoman as someone who excels in multiple roles, but the allocated importance to each role likely varies across them. Female influencers might highlight various roles in their posts but systematically emphasize certain roles more than others because they correspond to dominant values in their culture. To examine whether such cultural differences are present in the superwoman ideal, this study compared whether female influencers from the US, Belgium, and China differ in the roles they emphasize more (RQ5a) and whether cultural differences exist 
in the number of likes each of these roles receive (RQ5b). US-American and Chinese influencers were selected because they are both leading examples of a highly individualistic (i.e., US) and collectivistic culture (i.e., China; Schwartz, 2014). As their values are opposite to each other, comparing them will likely yield interesting results concerning how Western and non-Western cultures vary in their interpretation and disclosure of the superwoman ideal. Despite governmental restrictions, Instagram accounts for over 3,5 million users from mainland China, which are mostly adolescents and young adults (NapoleonCat, 2021). Additionally, influencers seem highly popular in this country, as most Chinese youth report following at least one influencer (Thomala, 2021). Therefore, knowledge of how Chinese influencers present themselves and their lifestyles on Instagram is important to understand how they possibly shape young Chinese women's ideas of the superwoman. Finally, Belgian influencers represent West European culture. Belgium was selected because of its international status and central position as the capital of the European Union (Bradford, 2020). Within this country and Europe in general, Instagram is one of the most popular social media applications, especially among adolescents and young adults (Statista, 2021a). Nearly one out of four Belgian young adults reported following or searching for influencers (Statista, 2021b). Moreover, Belgium is an individualistic country. However, compared to the US, it positions itself more moderately on typical individualistic values, such as power and competition (Schwartz, 2014). Thus, the popularity of influencers and moderate individualistic values make Belgium an interesting European case with which the disclosure of the superwoman ideal can be compared.

\section{Method}

\subsection{Sample}

To examine how the top female Instagram influencers frame their lifestyle, 60 profiles (i.e., 20 Flemish, 20 US American, and 20 Chinese) were analyzed $\left(M_{\text {age }}=26.02\right.$, $S D=2.73)$. The metrics of these accounts can be found online (see Supplementary Material). First, search terms related to health and beauty influencers were entered into the online search engine Google. The search terms included "top 10 popular Flemish beauty influencers" and "popular Chinese health influencers" (Boepple et al., 2016; Cohen et al., 2019). As we aimed to examine macro- and mega-influencers, the following selection criteria were used: a) a minimum of 10,000 followers, b) a minimum of 100 posts, and c) content related to fashion/beauty or exercising/food (Cohen et al., 2019; Oliveira et al., 2019). Per category, the first 10 influencers we encountered in rankings and who met the selection criteria were selected, ensuring variation in the content (e.g., food, fitness, yoga, make-up, fashion, and beauty products) and reach $(10,000-12,820,800$ follow- ers). Finally, the 20 most recent posts were retrieved, resulting in a final sample of 1,200 Instagram posts. Likes on posts tend to stabilize after approximately one day (Cotter, 2019; Yau \& Reich, 2019). Therefore the researchers ensured that the sampled posts remained online for at least two days at the moment of coding. Because embedded links were used during the coding process, a deleted post was replaced with the next most recent post of the influencer. Therefore, a small portion of the sample $(0.4 \%)$ was online for less than two days. The researchers examined only the first picture or video of a post.

\subsection{Qualitative Framing Analysis}

To explore recurring roles in female influencers' lifestyle presentations (RQ1a), an inductive framing analysis was conducted. The main goal was the construction of a frame package, which included a core frame, the reasoning devices, and the framing devices (Van Gorp, 2007). The core frame involves the central idea (i.e., role), while the framing devices refer to the indicators from which the core frame can be recognized (e.g., images). Finally, reasoning devices indicate the frame's conceptual content (e.g., definition). Together, these concepts form a cognitive scheme to properly interpret the message (Gamson \& Modigliani, 1989). To perform this analysis, a random subsample of $30 \%$ of the posts $(N=360)$ was selected.

\subsubsection{Analysis Procedure}

The framing analysis was performed in three phases by two experienced researchers (Corbin \& Strauss, 2008). First, posts were analyzed using an open coding system. All textual and visual elements of the posts were assigned individual codes. Next, codes that referred to similar presentations were combined as overarching roles (i.e., axial coding). This final list was checked for completeness by verifying whether each post could be classified under at least one specified role. Finally, frame packages were created based on the identified framing and reasoning devices and can be found online (see Supplementary Material). The frame itself referred to a specific role that was expressed through a combination of visual and textual elements. The researchers repeatedly re-evaluated the constructed frames until a saturation point was reached and no new frames could be detected.

\subsubsection{Six Dominant Roles}

The inductive framing analysis resulted in six core frames or roles. The first role, named "the beauty," focuses on the influencer herself and her beauty. This role is expressed through posts in which she is mostly alone and does not engage in meaningful activities (e.g., selfie). In the second role, named "the caring person," the influencer attempts to emphasize meaningful relationships (e.g., family and friends). This role is expressed through 
pictures with loved ones and expressing emotions toward them in the caption. In the third role, named "the busy bee," the influencer wants to be considered a busy and exciting person. This role is expressed through posts about noteworthy activities (e.g., social events and festivals). In the fourth role, named "the achiever," the influencer wants to be seen as a go-getter and hard worker. This role is expressed through posts about achievements (e.g., awards). In the fifth role, named "the role model," the influencer wants to be perceived as an inspiring person who encourages followers to improve themselves. This role is predominantly expressed through inspirational quotes in pictures or captions. The final role, named "the expert," emphasizes the influencer's expertise. She wants to portray herself as a knowledgeable and credible teacher. This role is expressed through posting, for example, beauty tips or food recipes.

\subsection{Quantitative Coding Analysis}

Next, a coding manual was developed to quantitatively analyze the complete sample of Instagram posts. In a preliminary phase, two independent coders tested the coding manual on a separate sample to compare coding decisions and resolve disagreements $(N=360, k=.73-1.00)$. Next, the first author extensively trained another independent coder, and each coded $20 \%$ of the full sample $(N=240)$ to evaluate intercoder reliability. The measures were reliable $(\kappa=.83-1$; McHugh, 2012).

\subsubsection{Coding Manual}

First, the number of likes was assessed. Next, sexualization was measured by coding the influencer's facial expression ( 1 = neutral, $2=$ sexy, $3=$ funny, or $4=$ smiling; Hund, 2017), visibility of body parts ( $0=$ none, $1=$ low body-ism, 2 = average body-ism, 3 = high body-ism, and $4=$ sexualized body parts), type of clothing ( $1=$ unrevealing, 2 = tight fit, 3 = medium revealing, and 4 = revealing), and amount of make-up $(0=$ no, $1=$ excessive, and $2=$ nat ural; Cohen et al., 2019; Smolak et al., 2014). Finally, the coder indicated whether or not $(0=$ no, $1=$ yes $)$ each of the roles were present. These roles were present when the post as a whole (i.e., picture/video and caption) clearly matched the definition. In cases where two (or more) roles appeared simultaneously, both were coded as present.

\subsection{Measures}

To accurately analyze differences in the number of likes between roles and across cultures (RQ3, RQ5b), a new variable (i.e., type of role) was created. The dichotomous roles were recoded into one categorical variable $(1=$ the beauty, 2 = the caring person, 3 = the busy bee, 4 = the achiever, $5=$ the role model, $6=$ the expert, and $7=a \mathrm{com}$ bination of roles). Moreover, to analyze differences in sexualization (RQ4), the four sexualization variables were transformed into dichotomous variables. Posts received a score of 1 if their facial expressions were sexy, their body parts were sexualized, their clothing was (medium) revealing, and they wore excessive make-up. Otherwise, they received a score of 0 on these variables. Afterwards, a new variable (i.e., level of sexualization) was created, with scores reaching from $0=$ not at all sexualized to 4 = extremely sexualized.

\subsection{Analytical Strategy}

The presence of roles across and within posts (RQ1b, RQ2) was analyzed using descriptive statistics. As the sample included multiple posts per influencer, multilevel models were conducted in $\mathrm{R}$ using the Ime4 package (Bates et al., 2015). To assess differences in the level of sexualization (RQ3), we performed a multilevel linear regression with "type of role" as the explanatory variable and "level of sexualization" as the outcome variable. Similarly, to examine whether the recognized roles differed in the number of likes they received (RQ4), we performed a multilevel linear regression with "type of role" as the explanatory variable and the number of likes as the outcome variable. Given that the number of likes varied considerably among the influencers, this variable was weighted. Posts thus scored a higher (positive) or lower (negative) number of likes compared to the average number of likes ( 0 ) the influencer received. To assess whether these differences are culturally dependent (RQ5b), an interaction term between "type of role" and culture was entered into the previous multilevel linear regression. The new variable "type of role," culture, and an interaction term between these two were thus included as categorical explanatory variables, while the number of likes was included as the outcome variable. Since R automatically dummy codes the categorical variables, such linear regressions allow us to compare each of the roles and cultures with the reference category. The reference category in this case was the first category listed. For the type of role, this reference category was the beauty, and for culture, it was American. The reference categories can be changed with the relevel() function (Bates et al., 2015). Finally, to assess cultural differences in the occurrence of roles (RQ5a), multilevel binary logistic regressions were conducted, with culture as a categorical explanatory variable and the roles as binary outcome variables. Similar to multilevel linear regressions, the categorical variable was also automatically dummy-coded, which allowed us to discover whether the likelihood of using a certain role differed between cultures.

\section{Results}

\subsection{Presence of Roles (RQ1b, RQ2)}

The beauty was present in $32.7 \%$ of the posts $(N=392)$ and was therefore the most highlighted role. The busy bee $(25.6 \%, N=307)$ and the expert $(17.9 \%, N=215)$ 
appeared to be the second and third most emphasized roles, while the caring person, the achiever, and the role model were less popular and present in $11.5 \%(N=138)$, $2.9 \%(N=35)$, and $0.9 \%(N=11)$ of the posts, respectively. In $7.4 \%$ of the posts $(N=90)$, multiple roles appeared simultaneously. The beauty and the busy bee $(4.4 \%, N=53)$ appeared to be the most used combination of roles (e.g., vacation bikini selfie). Another popular combination was the caring person and the busy bee (1.3\%, $N=16$; e.g., group of friends celebrating a festival).

\subsection{Differences in the Level of Sexualization (RQ3)}

According to the results, none of the posts were extremely sexualized, $0.2 \%$ were sexualized (i.e., score of three on sexualization), and $10.2 \%$ were moderately sexualized (i.e., score of two on sexualization). A few posts depicting the expert $(0.5 \%)$ and a combination of roles (1\%) were sexualized. Similarly, a minority of the posts depicting the beauty (18.4\%), the role model (9.1\%), the achiever (8.6\%), a combination of roles $(7.8 \%)$, the busy bee $(7.2 \%)$, the caring person (5.1\%), and the expert (4.2\%) were moderately sexualized.

Significant differences in sexualization were present $\left(x^{2}(6)=132.61, p<.001\right)$. The beauty was more sexualized than the caring person $(p<.001)$, the busy bee $(p<.001)$, the achiever $(p<.001)$, the role model $(p<.001)$, and the expert $(p<.001)$. The caring person was less sexualized than the busy bee $(p=.02)$ and a combination of roles $(p<.001)$. The busy bee was more sexualized than the expert $(p<.001)$ but less sexualized than a combination of roles $(p=.04)$. Finally, the role model $(p=.04)$ and the expert $(p<.001)$ were less sexualized than a combination of roles. An overview of all results can be found in Table 1.

\subsection{Differences in Number of Likes (RQ4)}

Significant differences in the number of likes were present as well $\left(x^{2}(6)=66.20, p<.001\right)$. The beauty received more likes than the busy bee $(p<.001)$, the role model $(p<.001)$, and the expert $(p<.001)$. Similarly, the caring person received more likes than the busy bee $(p=.02)$, the role model $(p<.001)$, and the expert $(p<.001)$. The busy bee, in turn, received fewer likes than the achiever $(p=.01)$ and a combination of roles $(p<.001)$ but more likes than the role model $(p<.001)$ and the expert $(p=.02)$. The achiever received more likes than the role model $(p<.001)$ and the expert $(p<.001)$, while the role model received fewer likes than the expert $(p=.03)$ and a combination of roles $(p<.001)$. Finally, the expert received fewer likes than a combination of roles $(p<.001)$. An overview of all results can be found in Table 2 .

\subsection{Cultural Differences (RQ5)}

The beauty, the caring person, and the role model were emphasized more in the posts of Chinese and
US-American influencers than Flemish ones. Next, the busy bee was emphasized more in the posts of Flemish and Chinese influencers, compared to US-American influencers. This difference appeared to be significant $\left(x^{2}(2)=13.98, p<.001\right)$ for both Flemish $(p<.001)$ and Chinese influencers $(p=.03)$. Flemish influencers were 3.11 times and Chinese influencers were 1.95 times more likely to emphasize the busy bee than US-American influencers. Moreover, the expert and the achiever occurred more in the posts of Flemish and US-American influencers than those of Chinese. For the achiever, this difference was significant $\left(x^{2}(2)=6.76, p=.03\right)$ for both US-American ( $p=.01)$ and Flemish influencers $(p=.03)$. Chinese influencers were 4.35 times less likely to emphasize this role compared to US-American influencers and 3.33 times less likely compared to Flemish influencers. An overview of all results can be found in Table 3. Finally, both culture $\left(x^{2}(2)=.17, p=.92\right)$ and the interaction term between type of role and culture $\left(x^{2}(12)=13.32, p=.35\right)$ were not significant predictors of differences in the number of likes.

\section{Discussion}

A framing analysis of 60 female Instagram influencers' profile posts $(N=1,200)$ revealed that they generally emphasize six roles in their presentations, which focus on their appearance (i.e., the beauty), relationships (i.e., the caring person), activities (i.e., the busy bee), achievements (i.e., the achiever), wisdom (i.e., the role model), and expertise (i.e., the expert). By highlighting these roles, influencers illustrate their excellence and compliance with the superwoman ideal. However, not all these roles seem to be equally important to focus on. The beauty, the busy bee, and the expert are the most commonly highlighted roles, meaning that it is most important to be beautiful, have an exciting life, and be an expert in your field. Similar to Fountaine's (2017) study, multiple roles often appear within one post to further emphasize their perfection in various life domains simultaneously.

Although the beauty, the busy bee, and the expert occur most frequently, the expert received fewer likes compared to the other roles. The achiever, the caring person, and the beauty received, on average, the most likes. In line with previous research, appearance and meaningful relationships are most appreciated by the audience (Park \& Lee, 2017). Furthermore, moderate forms of sexualization largely appear in posts highlighting beauty and to a lesser extent in other posts, which is not surprising given that beauty is mainly focused on appearance and therefore lends itself more to sexualization. Female influencers are presumably aware of the fact that sexualized content might be inconsistent with other, non-appearance-related roles and therefore reduce sexualized content to secure their status as a superwoman (Harrison \& Secarea, 2010). As beauty is the most common, the most popular, as well as the 
Table 1. Differences in sexualization between roles.

\begin{tabular}{|c|c|c|c|c|c|c|c|c|c|c|c|c|c|c|c|c|c|c|}
\hline & \multicolumn{3}{|c|}{1.} & \multicolumn{3}{|c|}{2.} & \multicolumn{3}{|c|}{3.} & \multicolumn{3}{|c|}{4.} & \multicolumn{3}{|c|}{5.} & \multicolumn{3}{|c|}{6.} \\
\hline & $B$ & $S E$ & $t$ & $B$ & $S E$ & $t$ & $B$ & $S E$ & $t$ & $B$ & $S E$ & $t$ & $B$ & $S E$ & $t$ & $B$ & $S E$ & $t$ \\
\hline $\begin{array}{l}\text { 1. The beauty } \\
M=.85\end{array}$ & - & - & - & & & & & & & & & & & & & & & \\
\hline $\begin{array}{l}\text { 2. The caring person } \\
M=.36\end{array}$ & $-.44 * * *$ & .06 & -7.25 & - & - & & & & & & & & & & & & & \\
\hline $\begin{array}{l}\text { 3. The busy bee } \\
M=.53\end{array}$ & $-.30 * * *$ & .05 & -6.47 & $.15^{*}$ & .06 & 2.31 & - & - & & & & & & & & & & \\
\hline $\begin{array}{l}\text { 4. The achiever } \\
M=.63\end{array}$ & $-.35^{* * *}$ & .11 & -3.28 & .09 & .11 & .80 & -.06 & .11 & -.52 & - & - & - & & & & & & \\
\hline $\begin{array}{l}5 . \text { The role model } \\
M=.18\end{array}$ & $-.55^{* * *}$ & .19 & -2.95 & -.11 & .19 & -.58 & -.26 & .19 & -1.37 & -.20 & .21 & -.95 & - & - & - & & & \\
\hline $\begin{array}{l}\text { 6. The expert } \\
M=.24\end{array}$ & $-.58^{* * *}$ & .06 & -10.37 & -.13 & .07 & -1.90 & $-.28 * * *$ & .06 & -4.87 & -.22 & .11 & -2.00 & -.02 & .19 & -.11 & - & - & - \\
\hline $\begin{array}{l}\text { 7. Combination } \\
M=.65\end{array}$ & -.14 & .07 & -1.96 & $.30 * * *$ & .08 & 3.61 & $.16 *$ & .07 & 2.09 & .21 & .12 & 1.73 & $.41^{*}$ & .20 & 2.10 & $.43 * * *$ & .08 & 5.45 \\
\hline
\end{tabular}

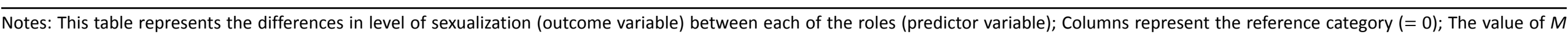
represents the average level of sexualization within each role (on a scale of 0 to 4 ) ${ }^{*} p<.05,{ }^{* *} p<.01,{ }^{* * *} p<.001$. 
Table 2. Differences in the number of likes between roles.

\begin{tabular}{|c|c|c|c|c|c|c|c|c|c|c|c|c|c|c|c|c|c|c|}
\hline & \multicolumn{3}{|c|}{1.} & \multicolumn{3}{|c|}{2.} & \multicolumn{3}{|c|}{3.} & \multicolumn{3}{|c|}{4.} & \multicolumn{3}{|c|}{5.} & \multicolumn{3}{|c|}{6.} \\
\hline & $B$ & $S E$ & $t$ & $B$ & $S E$ & $t$ & $B$ & $S E$ & $t$ & $B$ & $S E$ & $t$ & $B$ & $S E$ & $t$ & $B$ & $S E$ & $t$ \\
\hline $\begin{array}{l}\text { 1. The beauty } \\
M=38,652.50\end{array}$ & - & - & - & & & & & & & & & & & & & & & \\
\hline $\begin{array}{l}\text { 2. The caring person } \\
M=51,460.75\end{array}$ & -.06 & .09 & -.66 & - & - & - & & & & & & & & & & & & \\
\hline $\begin{array}{l}\text { 3. The busy bee } \\
M=23,333.85\end{array}$ & $-.29 * * *$ & .07 & -4.05 & $-.23 *$ & .10 & -2.38 & - & - & - & & & & & & & & & \\
\hline $\begin{array}{l}\text { 4. The achiever } \\
M=74,464\end{array}$ & .12 & .17 & .47 & .18 & .18 & 1.02 & $.42^{*}$ & .17 & 2.45 & - & - & - & & & & & & \\
\hline $\begin{array}{l}\text { 5. The role model } \\
M=19,407.45\end{array}$ & $-1.15^{* * *}$ & .29 & -3.95 & $-1.09 * * *$ & .29 & -3.65 & $-.85^{* *}$ & .29 & -2.93 & $-1.27 * * *$ & .33 & -3.86 & - & - & & & & \\
\hline $\begin{array}{l}\text { 6. The expert } \\
M=14,622.73\end{array}$ & $-.50 * * *$ & .08 & -6.17 & $-.44 * * *$ & .10 & -4.21 & $-.20 *$ & .08 & -2.42 & $-.62 * * *$ & .17 & -3.58 & $.65^{*}$ & .29 & 2.21 & - & - & \\
\hline $\begin{array}{l}\text { 7. Combination } \\
M=6,253.97\end{array}$ & .06 & .11 & .61 & .27 & .13 & 1.02 & $.36^{* *}$ & .11 & 3.29 & -.06 & .19 & -.31 & $1.21 * * *$ & .30 & 4.02 & $.56 * * *$ & .11 & 4.92 \\
\hline
\end{tabular}

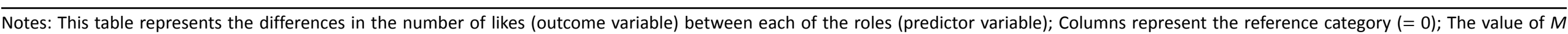
represents the average number of likes on each role; ${ }^{*} p<.05, * * p<.01, * * * p<.001$. 
Table 3. Cultural differences in the use of roles.

\begin{tabular}{|c|c|c|c|c|c|c|c|c|}
\hline & $B$ & $S E$ & OR & $\begin{array}{l}95 \% \text { Cl Lower } \\
\text { bound }\end{array}$ & $\begin{array}{l}\text { 95\% Cl Upper } \\
\text { bound }\end{array}$ & $\begin{array}{c}\text { Flemish } \\
\%\end{array}$ & $\begin{array}{c}\text { US American } \\
\%\end{array}$ & $\begin{array}{c}\text { Chinese } \\
\%\end{array}$ \\
\hline \multirow[t]{3}{*}{ 1. The beauty } & $-.08^{a}$ & $.40^{a}$ & $.92^{\mathrm{a}}$ & $.42^{\mathrm{a}}$ & $2.02^{a}$ & $21.5 \%$ & $36.3 \%$ & $40.3 \%$ \\
\hline & $.32^{\mathrm{b}}$ & $.39^{b}$ & $1.37^{b}$ & $.63^{b}$ & $2.97^{b}$ & & & \\
\hline & $-.39^{c}$ & $.40^{c}$ & $.67^{c}$ & $.31^{\mathrm{c}}$ & $1.47^{c}$ & & & \\
\hline \multirow[t]{3}{*}{ 2. The caring person } & $-.38^{\mathrm{a}}$ & $.37^{a}$ & $.68^{\mathrm{a}}$ & $.33^{\mathrm{a}}$ & $1.42^{\mathrm{a}}$ & $8.0 \%$ & $14.2 \%$ & $12.3 \%$ \\
\hline & $-.06^{b}$ & $.36^{\mathrm{b}}$ & $.94^{\mathrm{b}}$ & $.46^{b}$ & $1.92^{b}$ & & & \\
\hline & $-.33^{c}$ & $.37^{c}$ & $.72^{c}$ & $.35^{\mathrm{c}}$ & $1.50^{C}$ & & & \\
\hline \multirow[t]{3}{*}{ 3. The busy bee } & $1.13 * * * a$ & $.30^{\mathrm{a}}$ & $3.11^{a}$ & $1.71^{\mathrm{a}}$ & $5.65^{a}$ & $28.2 \%$ & $19.5 \%$ & $29 \%$ \\
\hline & $.67 * b$ & $.31^{b}$ & $1.95^{b}$ & $1.07^{\mathrm{b}}$ & $3.56^{b}$ & & & \\
\hline & $.46^{\mathrm{C}}$ & $.30^{c}$ & $1.59^{c}$ & $.89^{c}$ & $2.85^{c}$ & & & \\
\hline \multirow[t]{3}{*}{ 4. The achiever } & $-.23^{a}$ & $.42^{\mathrm{a}}$ & $.79^{a}$ & $.35^{\mathrm{a}}$ & $1.81^{\mathrm{a}}$ & $3.3 \%$ & $4.8 \%$ & $.8 \%$ \\
\hline & $-1.45^{* b}$ & $.56^{\mathrm{b}}$ & $.23^{\mathrm{b}}$ & $.08^{b}$ & $.71^{\mathrm{b}}$ & & & \\
\hline & $1.22^{*} \mathrm{c}$ & $.57^{c}$ & $3.39^{c}$ & $1.10^{c}$ & $10.46^{c}$ & & & \\
\hline \multirow[t]{3}{*}{ 5. The role model } & $-.25^{a}$ & $1.40^{\mathrm{a}}$ & $.28^{\mathrm{a}}$ & $.02^{\mathrm{a}}$ & $4.35^{a}$ & $.3 \%$ & $1.3 \%$ & $1.3 \%$ \\
\hline & $-1.28^{b}$ & $1.11^{\mathrm{b}}$ & $.78^{b}$ & $.09^{b}$ & $6.84^{b}$ & & & \\
\hline & $-1.03^{c}$ & $1.44^{\mathrm{C}}$ & $.36^{c}$ & $.02^{\mathrm{c}}$ & $5.99^{c}$ & & & \\
\hline \multirow[t]{3}{*}{ 6. The expert } & $.02^{\mathrm{a}}$ & $.45^{\mathrm{a}}$ & $1.02^{\mathrm{a}}$ & $.42^{\mathrm{a}}$ & $2.50^{a}$ & $19.5 \%$ & $22.8 \%$ & $11.5 \%$ \\
\hline & $-.76^{b}$ & $.47^{b}$ & $.47^{b}$ & $.19^{b}$ & $1.18^{b}$ & & & \\
\hline & $.78^{c}$ & $.47^{c}$ & $2.19^{c}$ & $.87^{c}$ & $5.48^{c}$ & & & \\
\hline
\end{tabular}

Notes: This table represents the differences in usage of roles (outcome variable) between each of the cultures (predictor variable); ${ }^{a}$ Flemish influencers compared to US-American influencers; ${ }^{b}$ Chinese influencers compared to US-American influencers; ${ }^{\mathrm{c}}$ Flemish influencers compared to Chinese influencers; ${ }^{*} p<.05,{ }^{* *} p<.01,{ }^{* * *} p<.001$.

most sexualized role, followers will probably acknowledge this role as most important to focus on (Wirtz et al., 2018). As such, the critique on the sexualized nature of female influencers is justified as the idea remains that, above all, one has to be beautiful and sexy (Pilgrim \& Bohnet-Joschko, 2019).

As young women are engaged in the process of identity formation, they might internalize the idea that they have to be superwomen to succeed in life (Heather, 2008). Therefore, knowledge of how influencers strategically frame their lifestyle is important, because such presentations presumably shape young women's understanding of what it means to be a superwoman (Heather, 2008). As such, they are constantly encouraged to excel in multiple domains (e.g., appearance and social life) to avoid the fear of not performing well enough (Glynn et al., 2009). This constant pressure possibly leads to role overload, which refers to the feeling of being overwhelmed by the high number of roles one has to manage (Glynn et al., 2009). However, such presentations might also be inspirational and encourage young women to improve themselves (Meier \& Schäfer, 2018). Future research should explore how influencers' superwomen presentations can both negatively and positively affect young women and under which circumstances such outcomes occur.
Finally, the most important roles (i.e., beauty, experience, and expertise) have an individualistic connotation, which supports the idea that the superwoman ideal is predominantly Western (Glynn et al., 2009; Mensinger et al., 2007). According to the results, small cultural differences exist regarding the roles of the busy bee and the achiever. In line with the literature on cultural orientations (Schwartz, 2014), US-American influencers seem less focused on exciting activities than Flemish and Chinese influencers but more focused on achievements. The absence of other cultural differences suggests that the superwoman ideal is similar across cultures, which supports the idea of the Westernization of cultural constructs, such as the superwoman ideal (Schroeder, 2016).

Although this study reveals interesting insights, some limitations exist. First, we focused only on Instagram, while other platforms (e.g., TikTok) generate different types of content and might therefore highlight different roles. Second, only persistent content was analyzed (e.g., pictures), while influencers presumably present themselves as less flawless in ephemeral content (e.g., stories) given the temporal nature of such content. Additionally, Instagram has recently added the option to conceal the number of likes on posts. At the time of sampling, this option was not yet available and therefore does not bias our results. However, future 
research should explore whether this option affects how influencers present themselves according to the superwoman ideal. Moreover, as Instagram is inaccessible to Chinese inhabitants, the selected Chinese influencers supposedly reside in a neighboring country or use a VPN to access Instagram. As they cannot properly reach their Chinese audience, they might have adapted their content to an international audience, which explains the absence of cultural differences. Finally, only health and beauty influencers were taken into account, which might explain the dominance of the appearance role. Future research should explore whether influencers on different topics (e.g., travel) provide different superwoman roles.

We can conclude that although beauty was the most important role that influencers emphasized, being a caring, exciting, high-achieving, inspiring, and knowledgeable person seems to be a substantial part of a superwoman as well. These roles are generalizable across cultures, which implies that young women worldwide are exposed to nearly identical presentations of what it means to be a successful superwoman.

\section{Acknowledgments}

This research was funded by a grant from the Flemish Fund for Scientific Research (FWO; G073017N). The authors would like to thank Ira Gielis for her assistance in the coding process and Drs. Luca Carbone and Dr. Kathrin Karsay for carefully reviewing the manuscript.

\section{Conflict of Interests}

The authors declare no conflict of interests.

\section{Supplementary Material}

Supplementary material for this article is available online at: https://osf.io/fzyge

\section{References}

APA Task Force on the Sexualization of Girls. (2007). Report of the APA task force on the sexualization of girls. American Psychological Association. http://www.apa.org/pi/women/programs/girls/ report-full.pdf

Bandura, A. (2001). Social cognitive theory of mass communication. Media Psychology, 3(3), 265-299. https://doi.org/10.1207/S1532785XMEP0303_03

Bates, D., Mächler, M., Bolker, B., \& Walker, S. (2015). Fitting linear mixed-effects models using Ime4. Journal of Statistical Software, 67(1), 1-48. https://doi.org/ 10.18637/jss.v067.i01

Boepple, L., Ata, R. N., Rum, R., \& Thompson, J. K. (2016). Strong is the new skinny: A content analysis of fitspiration websites. Body Image, 17, 132-135. https:// doi.org/10.1016/j.bodyim.2016.03.001

Bradford, A. (2020). The Brussels effect. Oxford Univer- sity Press. https://doi.org/10.1093/oso/97801900 88583.001.0001

Chae, J. (2018). Explaining females' envy toward social media influencers. Media Psychology, 21(2), 246-262. https://doi.org/10.1080/15213269.2017. 1328312

Cohen, R., Irwin, L., Newton-John, T., \& Slater, A. (2019). \#bodypositivity: A content analysis of body positive accounts on Instagram. Body Image, 29, 47-57. https://doi.org/10.1016/j.bodyim.2019.02.007

Corbin, J., \& Strauss, A. L. (2008). Basics of qualitative research: Techniques and procedures for developing grounded theory ( $3 r d$ ed.). SAGE.

Cotter, K. (2019). Playing the visibility game: How digital influencers and algorithms negotiate influence on Instagram. New Media \& Society, 21(4), 895-913. https://doi.org/10.1177/1461444818815684

De Lenne, O., Vandenbosch, L., Eggermont, S., Karsay, K., \& Trekels, J. (2018). Picture-perfect lives on social media: A cross-national study on the role of media ideals in adolescent well-being. Media Psychology, 23(1), 1-27. https://doi.org/10.1080/15213269. 2018.1554494

Djafarova, E., \& Trofimenko, O. (2019). "Instafamous": Credibility and self-presentation of micro-celebrities on social media. Information, Communication \& Society, 22(10), 1432-1446. https://doi.org/10.1080/ 1369118X.2018.1438491

Entman, R. M. (1993). Framing: Toward clarification of a fractured paradigm. Journal of Communication, 43(4), 51-58. https://doi.org/10.1111/j.1460-2466. 1993.tb01304.x

Fang, Y., \& Walker, A. (2015). "Full-time wife" and the change of gender order in the Chinese city. The Journal of Chinese Sociology, 2(1), 1-19. https://doi.org/ 10.1186/s40711-015-0006-x

Fountaine, S. (2017). What's not to like? A qualitative study of young women politicians' self-framing on Twitter. Journal of Public Relations Research, 29(5), 219-237. https://doi.org/10.1080/1062726X. 2017.1388239

Gamson, W. A., \& Modigliani, A. (1989). Media discourse and public opinion on nuclear power: A constructionist approach. American Journal of Sociology, 95(1), 1-37. https://doi.org/10.1086/229213

Glynn, K., Maclean, H., Forte, T., \& Cohen, M. (2009). The association between role overload and women's mental health. Journal of Women's Health, 18(2), 217-223. https://doi.org/10.1089/jwh.2007.0783

Harrison, L. A., \& Secarea, A. M. (2010). College students' attitudes toward the sexualization of professional women athletes. Journal of Sport Behavior, 33(4), 403-426. https://www.proquest.com/scholarlyjournals/college-students-attitudes-towardsexualization/docview/792665930/se-2? accountid $=17215$

Heather, A. K. (2008). Young women constructing identities: Multiple subject positions and the super- 
woman ideal. University of Calgary. https://www. collectionscanada.gc.ca/obj/thesescanada/vol2/ 002/NR44356.PDF

Hund, E. (2017). Measured beauty: Exploring the aesthetics of Instagram's fashion influencers. In A. Gruzd, J. Jacobson, \& P. H. Mai (Eds.), Proceedings of the 8th international conference on social media \& society (pp. 1-5). Association for Computing Machinery. https://doi.org/10.1145/3097286.3097330

Khamis, S., Ang, L., \& Welling, R. (2017). Self-Branding, "micro-celebrity" and the rise of social media influencers. Celebrity Studies, 8(2), 191-208. https://doi. org/10.1080/19392397.2016.1218292

Leban, M., Thomsen, T. U., von Wallpach, S., \& Voyer, B. G. (2020). Constructing personas: How high-networth social media influencers reconcile ethicality and living a luxury lifestyle. Journal of Business Ethics, 169(2), 223-225. https://doi.org/10.1007/ s10551-020-04485-6

Marwick, A. E. (2015). Instafame: Luxury selfies in the attention economy. Public Culture, 27(1), 137-160. https://doi.org/10.1215/08992363-2798379

Mascheroni, G., Vincent, J., \& Jimenez, E. (2015). “Girls are addicted to likes so they post semi-naked selfies": Peer mediation, normativity and the construction of identity online. Cyberpsychology, 9(1), Article 5. https://doi.org/10.5817/CP2015-1-5

McHugh, M. L. (2012). Interrater reliability: The Kappa Statistic. Biochemia Medica, 22(3), 276-282. https:// doi.org/10.11613/BM.2012.031

McRobbie, A. (2010). The aftermath of feminism: Gender, culture and social change. SAGE.

Meier, A., \& Schäfer, S. (2018). The positive side of social comparison on social network sites: How envy can drive inspiration on Instagram. Cyberpsychology, Behavior, and Social Networking, 21(7), 411-417. https://doi.org/10.1089/cyber.2017.0708

Mensinger, J. L., Bonifazi, D. Z., \& LaRosa, J. (2007). Perceived gender role prescriptions in schools, the superwoman Ideal, and disordered eating among adolescent girls. Sex Roles, 57(7), 557-568. https:// doi.org/10.1007/s11199-007-9281-9286

NapoleonCat. (2021). Instagram users in China. https:// napoleoncat.com/stats/instagram-users-in-china/ 2021/07

Northup, T., \& Liebler, C. M. (2010). The good, the bad, and the beautiful: Beauty ideals on the Disney and Nickelodeon channels. Journal of Children and Media, 4(3), 265-282. https://doi.org/10.1080/ 17482798.2010.496917

Oliveira, M., Barbosa, R., \& Sousa, A. (2019). The use of influencers in social media marketing. In R. Howlett \& L. C. Jain (Eds.), Marketing and smart technologies (pp. 112-124). Springer. https://doi.org/ 10.1007/978-981-15-1564-4_12

Park, H., \& Lee, J. (2017). Do private and sexual pictures receive more likes on Instagram? In International conference on research and innovation in informa- tion systems (ICRIIS) (pp. 1-6). IEEE. https://doi.org/ 10.1109/ICRIIS.2017.8002525

Pilgrim, K., \& Bohnet-Joschko, S. (2019). Selling health and happiness how influencers communicate on Instagram about dieting and exercise: Mixed methods research. BMC Public Health, 19(1), 1054-1054. https://doi.org/10.1186/s12889-019-7387-8

Scheufele, B. (2004). Framing-effects approach: A theoretical and methodological critique. Communications, 29(4), 401-428. https://doi.org/10.1515/ comm.2004.29.4.401

Schreurs, L., \& Vandenbosch, L. (2021). The development and validation of measurement instruments to address interactions with positive social media content. Media Psychology. Advance online publication. https://doi.org/10.1080/15213269.2021.1925561

Schroeder, R. (2016). The globalization of on-screen sociability: Social media and tethered togetherness. International Journal of Communication, 10, 5626-5643. https://ijoc.org/index.php/ijoc/article/ view/5729

Schwartz, S. H. (2014). National culture as value orientations: Consequences of value differences and cultural distance. In V. Ginsburgh \& D. Throsby (Eds.), Handbook of the economics of art and culture (Vol. 2, pp. 547-586). Elsevier. https://doi.org/10.1016/B978-0444-53776-8.00020-9

Singelis, T. M., Triandis, H. C., Bhawuk, D. P. S., \& Gelfand, M. J. (1995). Horizontal and vertical dimensions of individualism and collectivism: A theoretical and measurement refinement. Cross-Cultural Research, 29(3), 240-275. https://doi.org/10.1177/ 106939719502900302

Smolak, L., Murnen, S. K., \& Myers, T. A. (2014). Sexualizing the self. Psychology of Women Quarterly, 38(3), 379-397. https://doi.org/10.1177/03616843 14524168

Statista. (2021a). Distribution of total number of users of Instagram in Belgium as of July 2021, by age and gender. https://www.statista.com/statistics/ 946089/instagram-user-distribution-in-belgium-byage-group-and-gender

Statista. (2021b). Influence of social media advertising in Flanders (Belgium) 2020, by age. https:// www.statista.com/statistics/1100751/influence-ofsocial-media-advertising-in-flanders-by-age

Sumra, M. K., \& Schillaci, M. A. (2015). Stress and the multiple-role woman: Taking a closer look at the “superwoman." PLoS One, 10(3), Article e0120952. https://doi.org/10.1371/journal.pone.0120952

Tewksbury, D., \& Scheufele, D. A. (2009). News framing theory and research. In J. Bryant \& M. B. Oliver (Eds.), Media effects: Advances in theory and research (pp. 17-33). Erlbaum.

Thomala, L. L. (2021). Influencer following rate on social media in China 2020. Statista. https://www. statista.com/statistics/1200596/china-influencerfollowing-rate-on-social-media 
Van Gorp, B. (2007). The constructionist approach to framing: Bringing culture back in. Journal of Communication, 57(1), 60-78. https://doi.org/10.1111/ j.1460-2466.2006.00329.x

Wirtz, J. G., Sparks, J. V., \& Zimbres, T. M. (2018). The effect of exposure to sexual appeals in advertisements on memory, attitude, and purchase intention: A meta-analytic review. International Jour- nal of Advertising, 37(2), 168-198. https://doi.org/ 10.1080/02650487.2017.1334996

Yau, J. C., \& Reich, S. M. (2019). "It's just a lot of work": Adolescents' self-presentation norms and practices on Facebook and Instagram. Journal of Research on Adolescence, 29(1), 196-209. https://doi.org/ 10.1111/jora.1237

\section{About the Authors}

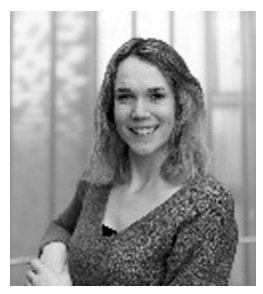

Sarah Devos (MA) is a PhD student at the School for Mass Communication Research of KU Leuven. Her research interests concern the relations between adolescents and young adults' (social) media use and well-being. Her PhD project specifically focuses on the malleability of success and happiness in traditional and social media and the consequences for adolescents' mental well-being.

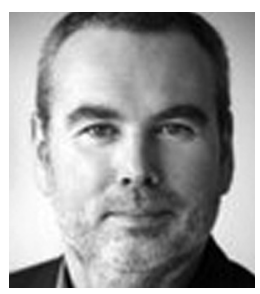

Steven Eggermont (PhD) is a full-time professor at the School for Mass Communication Research of KU Leuven. His research focuses on the media use of children and adolescents, sexual media contents, media use and health behaviors, and the effects of media exposure on attitudes and behaviors.

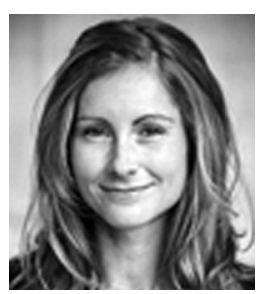

Laura Vandenbosch (PhD) is an assistant professor at the School for Mass Communication Research of KU Leuven (BOF-ZAP research professorship grant). The relationship between media and well-being is the core subject of her research, leading to international publications in several fields including developmental psychology, sexology, body image, social relationships, and communication theory. 